\title{
Chapter 3 \\ Validation of Screening Protocols for Heat Tolerance in Rice
}

\subsection{Background Analysis}

An alternative to screening for rice responses to heat at seedling and reproductive discussed in Chap. 2. This chapter covers further validation of identified lines through: (1) physiological and biochemical indicators that are reported to be associated with plant stress responses to classify the mechanism of heat tolerance of screened lines/varieties; (2) Field trials under real stress conditions provide conclusive data for screening and selection for advancing promising lines to confirm the methods developed in Chap. 2. Yield data were used to assess tested rice genotypes and comparisons made to heat tolerant/susceptible standards. Tested lines were classified as sensitive, intermediate and tolerant.

Biochemical changes are another aspect of plant acclimation to heat stress and heat stress may also affect leaf chlorophyll content and membrane stability through lipid peroxidation, leading to the production of peroxide ions and MDA (Wahid et al. 2007). Increasing the temperature changes of $37^{\circ} \mathrm{C} / 30{ }^{\circ} \mathrm{C}$ (day/night) increase the electrolyte leakage percentage and MDA content in rice (Zhang et al. 2009; Liu et al. 2013).

Identified lines/varieties were subjected to physiological and biochemical tests, such as electrolyte leakage, MDA level, total protein content, antioxidant enzymes (catalase, ascorbate peroxidase and superoxide dismutase) activity at seedling, vegetative stages and flowering stages. Results of the physiological and biochemical measurements confirmed heat tolerance behaviour of selected germplasm. This work was carried out at the Stress Physiology and Molecular Biology Laboratory of School of Life Sciences, Jawaharlal Nehru University New Delhi, India.

After screening at the seedling stage and/or flowering stages, the identified heat tolerant genotypes were tested in field conditions to evaluate real performance of selected promising lines in hot spot areas at various locations (in Cuba, Pakistan and UR Tanzania), known to experience heat stress. Field trials usually involve replicated plots that take up a lot of space and often in more than one location. Therefore, 
breeders need to be selective in what is to be tested. The pre-field screening protocols described in Chap. 2 provide potential candidates that may be advanced for field evaluations thus saving time, space and costs on lines with no potential.

\subsection{Validation of Physiological and Biochemical Indicators}

\subsubsection{Physiological and Biochemical Characterization of Heat Tolerant Lines at the Seedling Stage}

Physiological and biochemical changes to heat stress in rice include electrolyte leakage, lipid peroxidation level, MDA content and antioxidant enzyme activity (Campos et al. 2003; Heath and Packer 1986; Bajji et al. 2001; Nakano and Asada 1981; Oberley and Spitz 1985). Selected heat tolerant mutant lines of rice recorded a low level of electrolyte leakage thereby indicating less damage to membrane, as compared to the wild type parent medium heat tolerant IR64 (Fig. 3.1). Moreover MDA content (an indicator of lipid peroxidation) was assessed as a test for heat tolerance. It was observed that heat tolerant mutant lines showed relatively low MDA levels (Fig. 3.2). MDA is a reactive aldehyde and is one of the many reactive electrophile species that cause toxic stress in cells. Thus, the lower the level of MDA shows better plant performance. Antioxidant enzymes such as CAT and APX (ascorbate peroxidase) showed higher activity on the first day of heat stress treatment and SOD showed higher activities on the third day of heat stress treatment, as compared to wild type genotypes (Fig. 3.3) indicating a heat stress tolerant physiology.

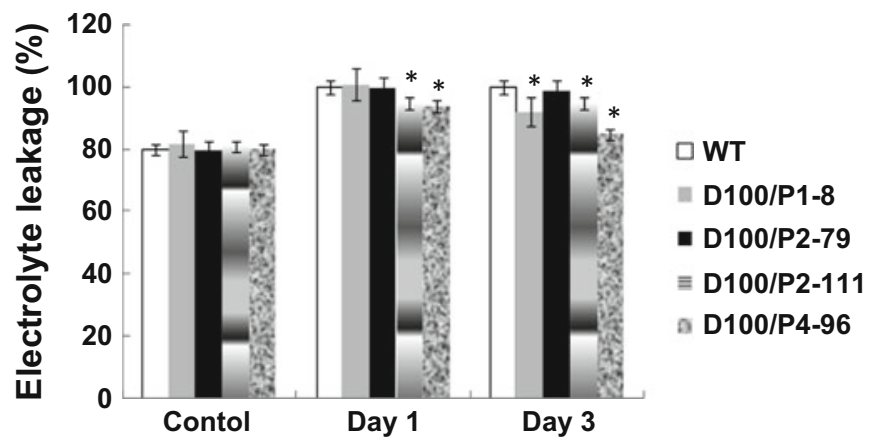

Fig. 3.1 Percentage electrolyte leakage in putative heat tolerant mutant lines as compared to IR64. Electrolyte leakage of IR64 under stress was taken as $100 \%$ and used as a reference to compare mutant lines. Day 1 and Day 3 indicate 1st day and 3rd day after heat stress treatment. The data represent means $\pm \mathrm{SE}$ of three biological replicates. Bars with stars are statistically significant $(\mathrm{p}<0.05)$ 


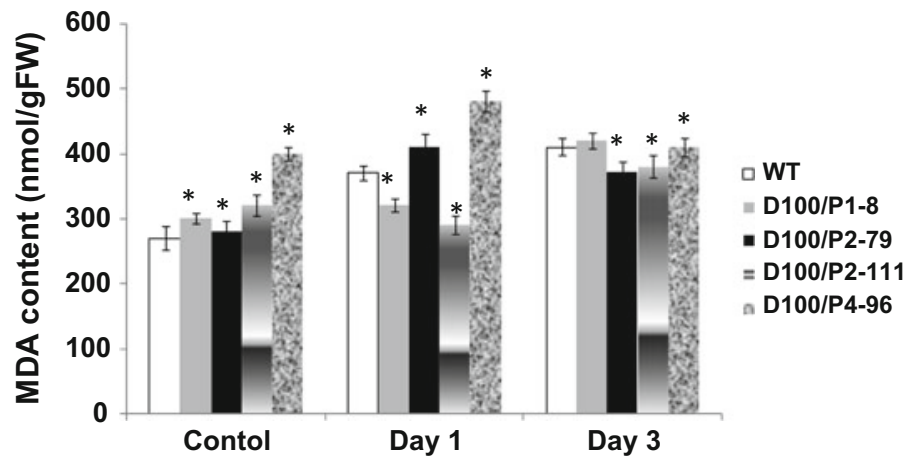

Fig. 3.2 MDA content in putative heat tolerant mutant lines compared to IR64. Day 1 and Day 3 indicate 1st day and 3rd day after heat stress treatment. The data represent means $\pm \mathrm{SE}$ of three biological replicates. Bars with stars are statistically significant $(\mathrm{p}<0.05)$

(a)

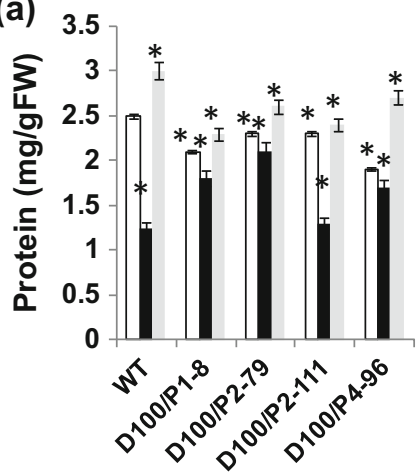

(c)

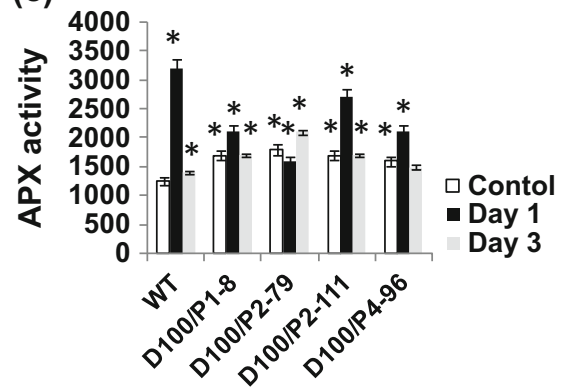

(b)

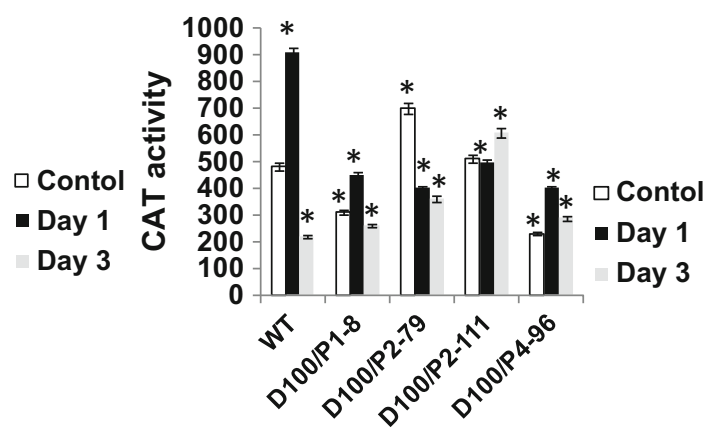

(d)

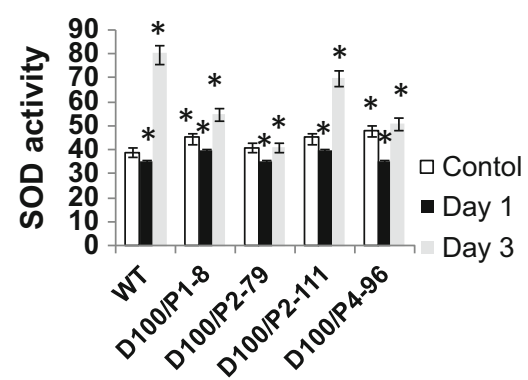

Fig. 3.3 Total protein content, CAT, APX and SOD activity in putative heat tolerant mutant lines as compared to wild type (IR64). Day 1 and Day 3 indicate 1st day and 3rd day after heat stress treatment. The data represent means $\pm \mathrm{SE}$ of three biological replicates. Bars with stars are statistically significant $(\mathrm{p}<0.05)$ 


\subsubsection{Physiological and Biochemical Characterization of Heat Tolerant Lines at the Flowering Stage}

Before heat treatments at flowering of the putative heat tolerant lines (D100/P1-8, D100/P1-79, D100/P2-111, D100/P4-96), an assessment was made for membrane stability at the late vegetative stage. Electrolyte leakage was similar in all genotypes in control conditions, but the heat tolerant lines had superior electrolyte leakage than the wild type standard under heat stress conditions (Fig. 3.4).

Morphological and biochemical analysis of putative heat tolerant mutant plants were analysed at the flowering stage as this is a temperature sensitive stage (Jagadish et al. 2007). The mutants phenotype were analysed under optimum temperatures in glasshouse conditions immediately after heat stress treatment $\left(40{ }^{\circ} \mathrm{C}\right.$ for $\left.4 \mathrm{~h}\right)$ and after recovery $\left(72 \mathrm{~h}, 28^{\circ} \mathrm{C}\right)$. The putative heat tolerant mutants performed better than their wild type parent (Fig. 3.5). The mutant plants were healthy and continued to grow after the heat stress treatment, whereas a reduction in growth was observed in wild type plants after heat stress and during the recovery period. Data on panicle length, height, number of tillers and number of seeds per panicle were found to be superior in the heat tolerant mutants than for wild type (Fig. 3.5). The putative mutant lines also produced more vegetative and reproductive growth under normal as well as heat stress conditions, indicating that tolerance to heat stress was constitutive.

Anthesis in rice is very sensitive to heat stress (Jagadish et al. 2007). Putative heat tolerant mutants performed better than their wild type parent under heat stress at the flowering stage. Phenotypic data were recorded in control optimum temperature conditions, immediately after heat stress treatment $\left(40{ }^{\circ} \mathrm{C}\right.$ for $\left.4 \mathrm{~h}\right)$ for three subsequent days (to span main panicle flowering) and after recovery $\left(72 \mathrm{~h} 28^{\circ} \mathrm{C}\right.$ ). Besides healthier appearance and better growth, the putative heat tolerant mutants recorded higher spikelet fertility and yield components such as panicle length, number of

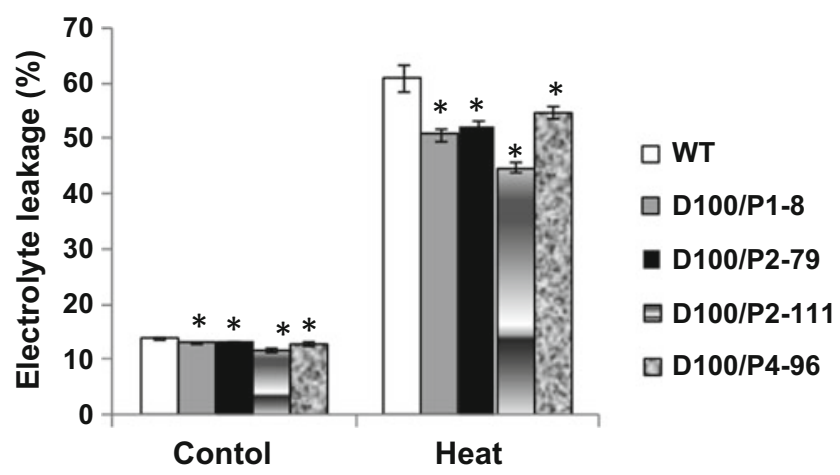

Fig. 3.4 Electrolyte leakage (\%) of putative heat tolerant lines at pre-flowering stage. The data represent means $\pm \mathrm{SE}$ of three biological replicates. Bars with stars are statistically significant $(\mathrm{p}<0.05)$ 
(a)

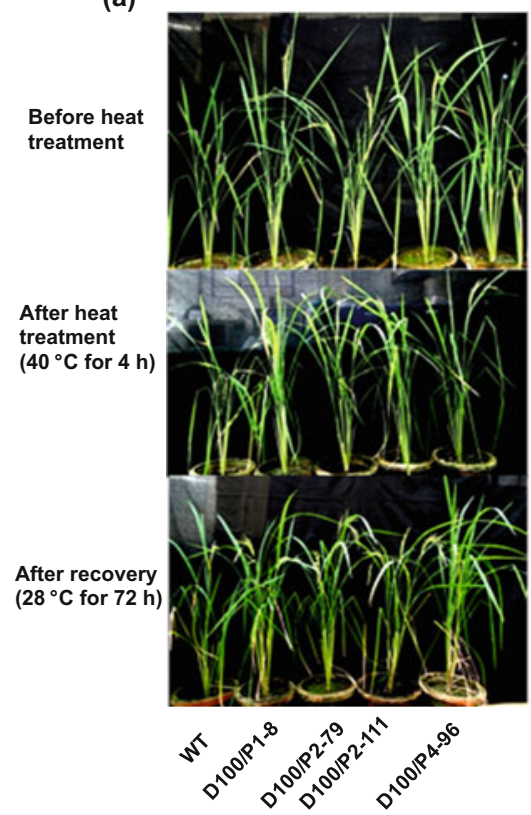

(b) WT D100/P1-8 D100/P2-79 D100/P2-111 D100/P4-96

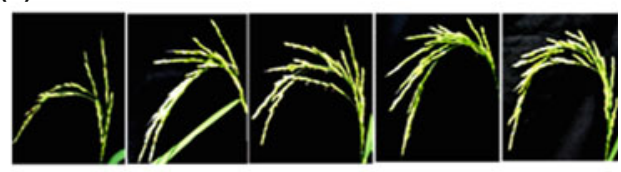

(c)
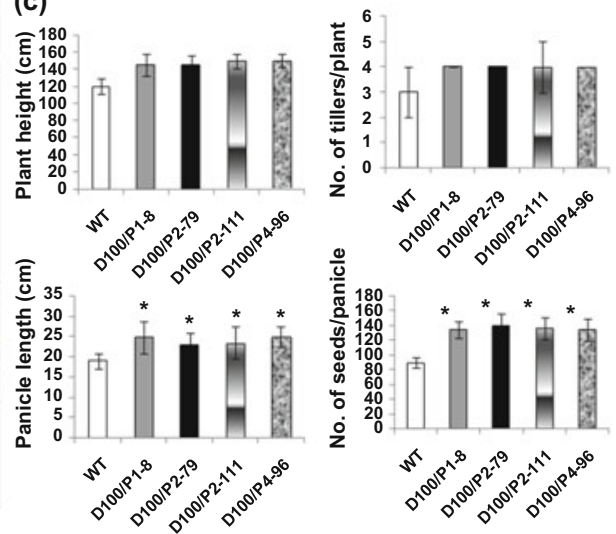

Fig. 3.5 Morphology and morphological parameter analysis of heat tolerant mutants. (a) Wild type and heat tolerant mutants before stress, immediately after stress and during the recovery phase. (b) Panicle phenotype of wild type and heat tolerant mutants after recovery. (c) Different morphological parameters in wild type and heat tolerant mutants after recovery. The data represent means $\pm \mathrm{SE}$ of three biological replicates. Bars with stars are statistically significant $(\mathrm{p}<0.05)$

tillers, and number of spikelets per panicle grain yield and plant height per plot as compared to wild type. The mutant lines had a higher vegetative and reproductive growth under both normal and heat stress conditions, suggesting that the genetic controls were constitutive.

\subsubsection{Methods}

\subsubsection{Electrolyte Leakage Measurement}

Analysis of electrolyte leakage is carried out following the protocol of Bajji et al. (2002). Leaf samples from control and heat-treated plants are harvested and washed with distilled water to remove any surface adhering ions. About $100 \mathrm{mg}$ of the tissue are dipped immediately into $20 \mathrm{ml}$ of de-ionized water. After incubating the leaf tissues at $37^{\circ} \mathrm{C}$ for $2 \mathrm{~h}$, the electrical conductivity (E1) of the immersion solution is measured using a conductivity meter (ELEINS, Inc., India). To determine the total conductivity (E2), the samples with immersion solution (effusate) are autoclaved for $15 \mathrm{~min}$ at $121{ }^{\circ} \mathrm{C}$ and the conductivity of the effusate is measured after cooling it to room temperature. Relative electrical conductivity is measured by the formula: percentage of electrolyte leakage $=\mathrm{E} 1 / \mathrm{E} 2 \times 100$. 


\subsubsection{Lipid Peroxidation Assay}

Lipid peroxidation is estimated measuring the formation of MDA. MDA content is quantified by thiobar-bituric acid reactive substances assay (Heath and Packer 1986; Larkindale and Knight 2002). For this, about $100 \mathrm{mg}$ of leaf tissue from the control and heat-treated plants is homogenized in $5 \mathrm{~mL}$ of $5 \%(\mathrm{w} / \mathrm{v})$ trichloroaceticacid and the homogenate centrifuged at $12,000 \times \mathrm{g}$ for $10 \mathrm{~min}$ at room temperature. The supernatant is mixed with an equal volume of thiobarbituric acid [0.5\% in $20 \%$ (w/v) trichloroaceticacid] and the mixture is then boiled for $25 \mathrm{~min}$ at $100{ }^{\circ} \mathrm{C}$, followed by centrifugation for $5 \mathrm{~min}$ at $7500 \mathrm{~g}$ to clarify the solution. Absorbance of the supernatant is measured at $532 \mathrm{~nm}$. MDA equivalents are calculated by the extinction coefficient of $155 \mathrm{mM}^{-1} \mathrm{~cm}^{-1}$.

\subsubsection{Measurement of Total Proteins}

Total soluble proteins are extracted from the rice leaves $(100 \mathrm{mg})$ of heat treated plants at the seedling stage using Zivy's buffer (Zivy et al. 1983). Amount of soluble proteins is estimated by Bradford's assay (Bradford 1976) with the help of the standard curve prepared using various known concentrations of other protein, such as Bovine Serum Albumin (BSA fraction V), prepared by using different concentration of Bovine Serum Albumin (Ernst and Zor 2010).

\subsubsection{Antioxidant Enzyme Activity Assay}

About $100 \mathrm{mg}$ leaf material from the heat treated plants was homogenized in ice-cold $50 \mathrm{mM}$ K-PO 4 buffer (pH 7.5) containing $2 \mathrm{mM}$ EDTA and $0.1 \mathrm{mM}$ phenylmethylsulphonylfloride (PMSF). The homogenizing buffer for APX additionally contained $2 \mathrm{mM}$ of Na-ascorbate. The homogenate was centrifuged at $12,000 \times g$ for $10 \mathrm{~min}$ at $4{ }^{\circ} \mathrm{C}$ and the supernatant was used for enzyme assay. Total protein content in supernatant was determined following the method of Bradford (1976). The activity of SOD was measured using the method of Giannopolitis and Reis (1977). The assay mixture $(1 \mathrm{~mL})$ for SOD contained $79.2 \mathrm{mM}$ Tris-HCI buffer $(\mathrm{pH} 8.9)$, containing $0.12 \mathrm{mM}$ EDTA, $10.8 \mathrm{mM}$ tetra ethylene diamine, bovineserum albumin (3\%), $6 \mathrm{mM}$ nitroblue tetrazolium (NBT), $60 \mu \mathrm{M}$ riboflavin in $5 \mathrm{mM} \mathrm{KOH}$ and $5 \mu \mathrm{g}$ of enzyme extract. The increase in absorbance due to formazan formation was read at $560 \mathrm{~nm}$. The increase in absorbance in the absence of enzyme was taken as 100\%, and 50\% initial was taken as equivalent to 1 unit of SOD activity. APX activity was determined according to Nakano and Asada (1981). The reaction mixture in a total volume of $1 \mathrm{ml}$ consisted of $50 \mathrm{mM}(\mathrm{pH} 7.5)$ K-PO4buffer, $0.1 \mathrm{mM}$ EDTA, $0.25 \mathrm{mM}$ ascorbate, $10 \mathrm{mM} \mathrm{H}_{2} \mathrm{O}_{2}$ and enzyme extract. $\mathrm{H}_{2} \mathrm{O}_{2}$-dependent oxidation of ascorbate was followed spectrophotometrically by recording the decrease in absorbance at $290 \mathrm{~nm}\left(\mathrm{D}=2.8 \mathrm{mM}^{-1} \mathrm{~cm}^{-1}\right)$. Slope values of absorbance in $290 \mathrm{~nm}$ are considered for rate calculation. Catalase (CAT) activity was determined 
following the method of Aebi (1983) by measuring the decrease in absorbance at $240 \mathrm{~nm}$ due to the decomposition of $\mathrm{H}_{2} \mathrm{O}_{2}\left(\mathrm{D}=40 \mathrm{M}^{-1} \mathrm{~cm}^{-1}\right)$. The slope value of the rapid decline in $240 \mathrm{~nm}$ absorption was considered for rate calculation. The reaction mixture in $1 \mathrm{ml}$ contained $50 \mathrm{mM} \mathrm{K}-\mathrm{PO}_{4}$ buffer $(\mathrm{pH} 7.0)$ with leaf extract equivalent to 4-5 $\mu \mathrm{g}$ protein. The reaction was initiated by adding $\mathrm{H}_{2} \mathrm{O}_{2}$ to a final concentration of $20 \mathrm{mM}$. All the experiments involved in physiological and biochemical analyses were repeated three times using three independent mutant plants from each line.

\subsection{Validation Protocols of Rice Heat Tolerance Under Field Conditions}

After screening at the seedling stage and flowering stages (as described in Chap. 2) identified heat tolerant genotypes were tested in field conditions to validate the pre-field screening protocols in hotspot test locations.

The field trials were conducted in different places which were known for heat stress in Cuba, Pakistan and UR Tanzania. Field experiments were planted in completely randomized block designs with three or four replications per location. To further verify the results of seedling and reproductive stages screening protocols data were collected on:

- Time of day for flowering (anthesis)

- Plant height

- Number of tillers per plant

- Panicle length

- Spikelet number of the main tiller panicle

- Spikelet fertility (ratio of filled/unfilled grains)

- Thousand kernel weight

- Paddy yield

Data were recorded for plant height; number of productive tillers per plant, panicle length, and spikelet per main panicle, panicle fertility, thousand seed weight and yield were recorded. From these data the tested genotypes including mutant lines were categorized as below (Tables 3.1, 3.2 and 3.3).

Screened lines were evaluated for various agro-morphological characters in field tests and compared to standards including local cultivars and parental lines at different locations and years. Temperature and rainfall of the locations were recorded and compared with long term temperature means. Comparisons were made for yield performance as well as yield components such as spikelet number, thousand kernel weight and filled/unfilled grain ratio under natural high temperature conditions. The results of field screening confirmed the results of the laboratory (physiological and biochemical) testing and also pre-field screening results at both the seedling and flowering stage. 
Table 3.1 Classification of heat tolerance of rice genotypes in field conditions at NIAB, Pakistan compared to medium heat tolerant standard cv. IR64

\begin{tabular}{l|l|l}
\hline $\begin{array}{l}\text { More susceptible than } \\
\text { control cv. IR64 }\end{array}$ & Equivalent to control cv. IR64 & $\begin{array}{l}\text { More tolerant } \\
\text { than control } \\
\text { cv. IR64 }\end{array}$ \\
\hline $\begin{array}{l}\text { HS cv. 'Super } \\
\begin{array}{l}\text { Basmati', tested } \\
30 \text { mutant lines }\end{array}\end{array}$ & $\begin{array}{l}\text { IR 64, HT-18, HT-29, HT-31, HT-39, HT-51, } \\
\text { HT-53, HT-98, HT-104, HT-114, HT-119, }\end{array}$ & $\begin{array}{l}\text { HT-74, HT-81, } \\
\text { HT-92 and } \\
\text { HT-97 }\end{array}$ \\
\hline
\end{tabular}

Table 3.2 Classification of heat tolerance rice genotypes in field conditions at INCA, Cuba compared to the control parent and local cultivars

\begin{tabular}{l|l|l}
\hline $\begin{array}{l}\text { More susceptible than control } \\
\text { parent and local cultivars }\end{array}$ & $\begin{array}{l}\text { Equivalent to control } \\
\text { parent and local cultivars }\end{array}$ & $\begin{array}{l}\text { Tolerant/better than control } \\
\text { parent and local cultivars }\end{array}$ \\
\hline LP-16, A 82 & $\begin{array}{l}\text { 8551, 8554, 8555, LP-10, } \\
\text { LP 9, LP-7, LP 8, }\end{array}$ & $\begin{array}{l}\text { 8553,LP12,8552,8555 } \\
\text { Guillemar }^{\mathrm{a}}\end{array}$ \\
\hline
\end{tabular}

${ }^{\mathrm{a}}$ Guillemar cv. released as heat tolerant variety in 2015 in Cuba

Table 3.3 Classification of heat tolerance of rice genotypes compare to parental (wild type) genotypes and HT sensitive cv. WAB 56-104 under field conditions from Sokoine University, URT Tanzania

\begin{tabular}{l|l|l}
\hline $\begin{array}{l}\text { More susceptible than control } \\
\text { WAB 56- and parent }\end{array}$ & $\begin{array}{l}\text { Equivalent to control cv } \\
\text { WAB 56-104 }\end{array}$ & $\begin{array}{l}\text { More tolerant than control } \\
\text { cv WAB 56-104 }\end{array}$ \\
\hline KR, WAB56-50, WAB56- & KR-27, WAB56-50-51, & WAB56-50-85-3, WAB56- \\
104, WAB56-50-104-36-1, & WAB56-50-97, WAB56-50- & 50-82-1, WAB56-50-74-1, \\
KR 38-1 WAB56-50-127-3, & 123, WAB56-50-127, & WAB56-50-56-1, WAB56- \\
WAB56-50-98-1, KR 27-1 & WAB56-50-135, KR-37, & $\begin{array}{l}104-36-1, \text { WAB56-104-141- } \\
\text { WAB56-104-9 }\end{array}$ \\
& & 1, WAB56-104-141-3, \\
& & WAB56-50-127-3, WAB6- \\
& & 2, WAB56-56-1, WAB56-104-141- \\
\hline
\end{tabular}

Open Access This chapter is licensed under the terms of the Creative Commons Attribution 3.0 IGO license (https://creativecommons.org/licenses/by/3.0/igo/), which permits use, sharing, adaptation, distribution and reproduction in any medium or format, as long as you give appropriate credit to the International Atomic Energy Agency (IAEA), provide a link to the Creative Commons license and indicate if changes were made.

Any dispute related to the use of the works of the IAEA that cannot be settled amicably shall be submitted to arbitration pursuant to the UNCITRAL rules. The use of the IAEA's name for any purpose other than for attribution, and the use of the IAEA's logo, shall be subject to a separate written license agreement between the IAEA and the user and is not authorized as part of this CCIGO license. Note that the link provided above includes additional terms and conditions of the license.

The images or other third party material in this chapter are included in the chapter's Creative Commons license, unless indicated otherwise in a credit line to the material. If material is not included in the chapter's Creative Commons license and your intended use is not permitted by statutory regulation or exceeds the permitted use, you will need to obtain permission directly from the copyright holder. 